\title{
Smart Mechanism Design of Electric Energy Meter Adaptive Sealing Device
}

\author{
Jin Zhang ${ }^{1}$, Wen Zhao ${ }^{2}$ and Changyou $\mathrm{Hu}^{3, *}$ \\ ${ }^{1}$ Chongqing Electric Power Science Research Institute, Chongqing, China, 404100 \\ ${ }^{2}$ Sichuan Fude Robot Co., Ltd., Mianyang, Sichuan, China, 621010 \\ ${ }^{3}$ Southwest University of Science and Technology, Mianyang, Sichuan, China, 621010 \\ ${ }^{*}$ Corresponding author
}

\begin{abstract}
At present, sealing of electric energy meters mainly uses the manual operation, which leads to poor quality and low efficiency, there is an urgent need to develop automatic sealing equipment with compact structure and adaptability. After the analysis of overall requirements and mechanism structure, smart mechanism of electric energy meter adaptive sealing of automatic sealing device is studied, and then the threading and sealing mechanism, feeding mechanism and seal guiding mechanism are designed.
\end{abstract}

Keywords-electric energy meter sealing; threading; sealing; feeding; seal guiding

\section{INTRODUCTION}

With the major power grid companies to vigorously promote the power grid intelligent, automated, information technology, a large number of smart meters have been standardized to promote the application.In order to meet the production needs, energy meter verification work also need to achieve automation, therefore, part of the power supply bureau has also started to build energy meter automatic test assembly line.

Energy meter sealing is an important process where the energy meter production and verification process , it is required to install the seal in the production before the factory and after passing the test.The traditional sealing system has the limitation of labor force, low efficiency, poor production quality and low accuracy of production data. These problems will become the bottleneck of the whole process automation of the metering test. Therefore, the automatic energy meter system R \& D has also become an inevitable trend.

In this paper, according to the demand analysis of the automatic sealing device of the electric energy meter, the selfadaptive sealing and smart mechanism of the automatic sealing device is studied, and the wear silk and sealing mechanism, the wire feeding mechanism and the seal guide mechanism are designed in detail.

\section{Automatic SEALing DeVICE InTROduction AND DEMAND DESCRIPTION}

Currently meet the national standard smart meters, including single-phase and three-phase meters, requiring the design of the energy meter automatic sealing device can be compatible with these two types of energy meter.In addition, the equipment is also small and practical, with good adaptive ability, fault-tolerant processing power, high reliability and high efficiency.Through the promotion and application of the automatic sealing device, to improve the energy meter seal sealing efficiency and seal quality, reduce the energy meter verification seal part of the cost.

The design of the energy meter automatic sealing device shown in Figure 1.The device mainly includes screw nail on the hole system, wearing silk seal system, wire feeding system, lead block diversion system. Which screw nail on the hole system mainly by the servo motor and industrial camera system components, to realize the screw automatic hole alignment of the electric meter;Wearing silk seal system is mainly composed of wire feeding mechanism, wire drawing mechanism, centering mechanism and guide wire mechanism, to achieve the wire to wear and seal the work.The wire feeding system is an auxiliary system for wearing silk seal system, providing a sealing wire for the threading seal system;The lead block diversion system mainly consists of lead block feeding mechanism, laser marking machine, two-dimensional code recognition intelligent camera, diversion tube and so on, to achieve the two-dimensional code coding and identification records and lead block feeding.

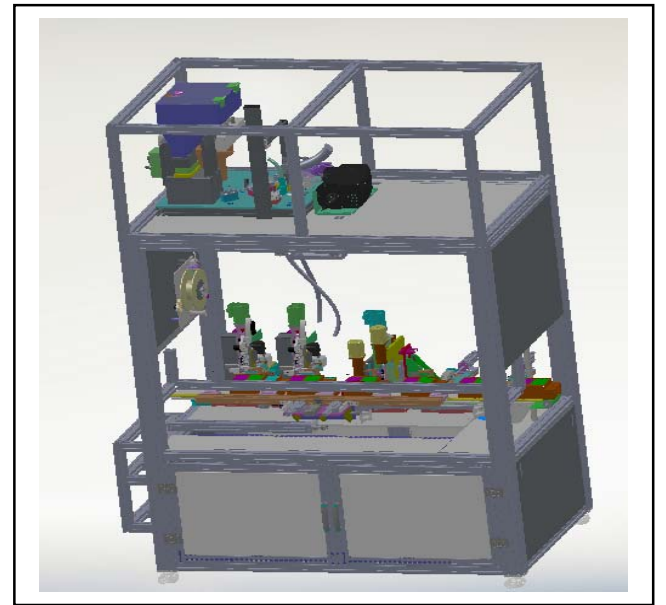

FIGURE I. POWER METER AUTOMATIC SEALING DEVICE THREE DIMENSIONAL STRUCTURE

Figure 2 shows the system workflow.Automatic sealing system operation process is as follows: unsealed energy meter 
first by screwing the hole system processing, and get hole deviation information, vibration plate feeding lead block to the laser coding system, the lead block through the twodimensional code after the coding and identification, and then through the lead block guide tube to wear silk sealing mechanism, and finally, wear silk sealing mechanism will reach the energy meter, wire feeding mechanism of the wire and lead block, according to the nail to the hole passing the hole deviation, through the more complex and smart action combination, to achieve wear and pressure seal work, to achieve the automatic sealing of the energy meter work.

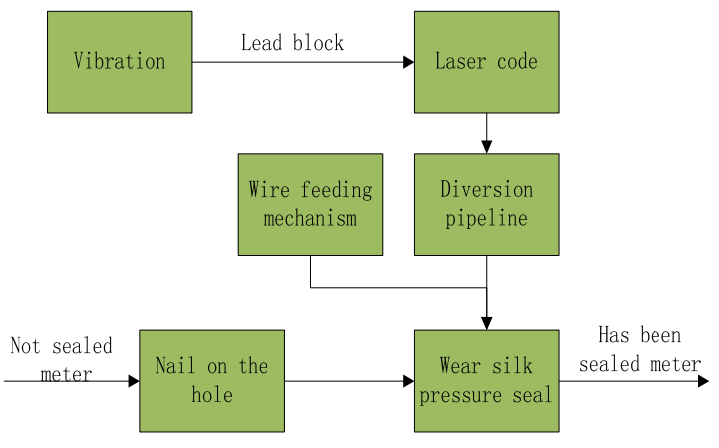

FIGURE II. SYSTEM WORKFLOW

This article is mainly aimed at the core mechanism of automatic sealing device for detailed design, that is, wearing silk pressure sealing, wire feeding mechanism and lead block diversion mechanism.

\section{WEARING AND SEALING MECHANISM DESIGN}

Figure 3 shows the three-dimensional design of the threading and sealing mechanism. The main part of the body by the wear silk module, take the wire module, riveting pressure module and tailoring module.

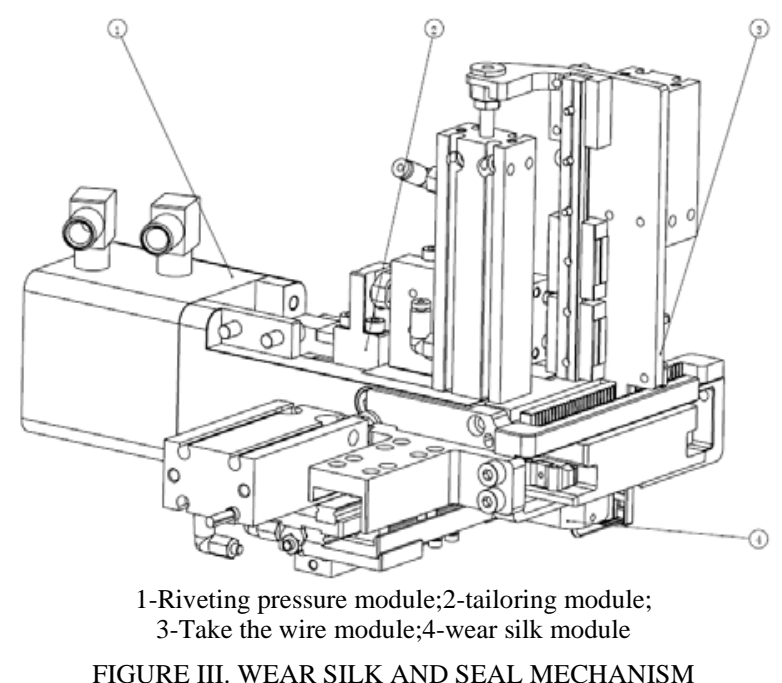

Automatic wear silk sealing system work, the seal obstruct components work, The cylinder is extended to the stop position.The seal feed device delivers a qualified seal to the seal station.The wire feeder sends the qualified thread to the riveting device, through the guide part of the riveting device to pass the thread through the hole of the meter to be sealed, and the threading module will extract the thread.Then the threading mechanism in the riveting assembly begins to work, and the thread is structured into the two slots of the seal by means of the rack and pinion mechanism.Ready to riveting pressure after the start, will seal riveting pressure and cut off the excess thread.Finally, the seal stop the cylinder of components back, riveting pressure seal will follow the meter flow together, waiting for the next process of processing.At this point the entire sealing action is completed.Among them, the whole threading and sealing mechanism is difficult to take silk and riveting pressure process, the following to a detailed description for this modules.

The wire taking module is shown in Figure 4 and consists of cylinder 11, cylinder 12, rail and several parts. When the wire is taken, the cylinder 12 is moved downwardly to the take-up position(the cylinder 11 is retracted). When the silk thread is in place, the cylinder 11 is extended and the silk thread is held and the cylinder 12 is extended to lift the silk thread upward.

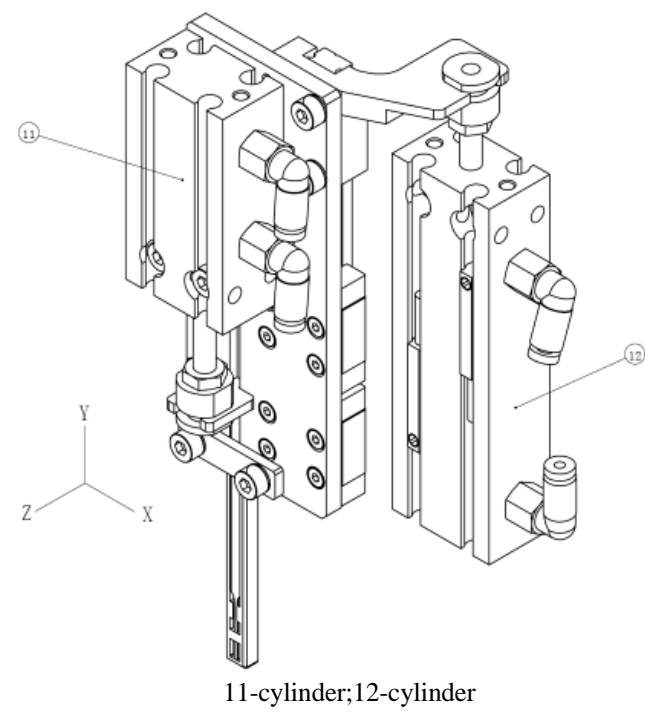

FIGURE IV. TAKE THE SILK THREAD MODULE

The riveting module is composed of a hydraulic cylinder 1 , an air cylinder 2 , a right rack 3 , a left rack 4 , a gear 5 , a rotary shaft 6 , a guide rail 7, and a cylinder 8 as shown in Figure 5.The module mainly to achieve the regular wire and seal the riveting pressure.

Which is the regulation of the wire will be through the wire of the wire gauge to the seal slot, to ensure that each seal is valid, qualified.This part of the function by the cylinder 8 , guide 7 , shaft 6 , gear 5 , rack 4 , rack 3 to achieve. When the cylinder 8 is extended, the rack is transported along the guide rail 7 , and the thread is transported in the direction of the $\mathrm{Z}$ cylinder to the direction of the seal.While the other side of the rack 3 will be through the gear drive, along the cylinder movement in the opposite direction of movement, the other side of the wire into the seal of the slot.

The purpose of the seal riveting pressure is to have been finishing the wire and seal riveting together, through the 
hydraulic cylinder 1 to the right to move to achieve this function.

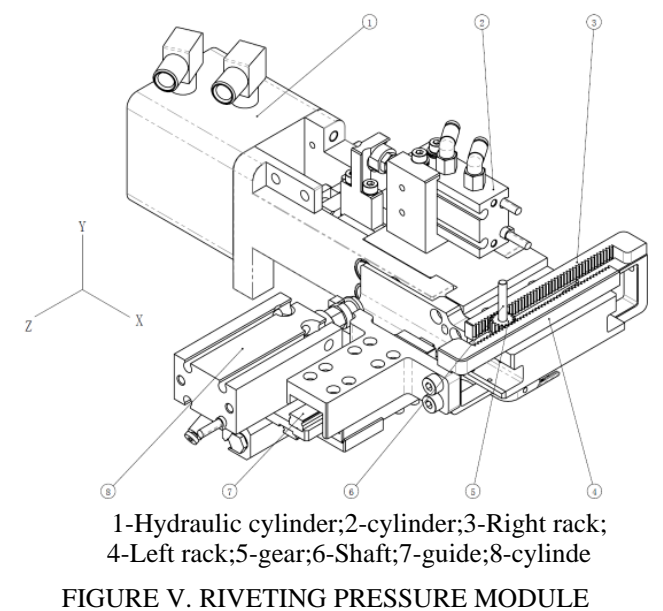

\section{DESIGN OF WiRE FEEDING MECHANISM}

As shown in Figure 6, the wire feed mechanism comprises five main structures, namely, a wire feed device, a straightening device, a cable unit 1 , a fixing device, and an automatic cable pulling device 2, respectively.Automatic feeding system work, the sealing wire has passed wire device, straightening device, cable device 1 , fixed length device, automatic cable device 2.When the sealing wire needs to be outputted, the cable device 2 is automatically rotated and the wire is fed out.At the same time the encoder detects the length of the wire and feeds back to the computer. If the desired length is reached, the computer will give an instruction to stop the automatic cable device 2 from rotating.

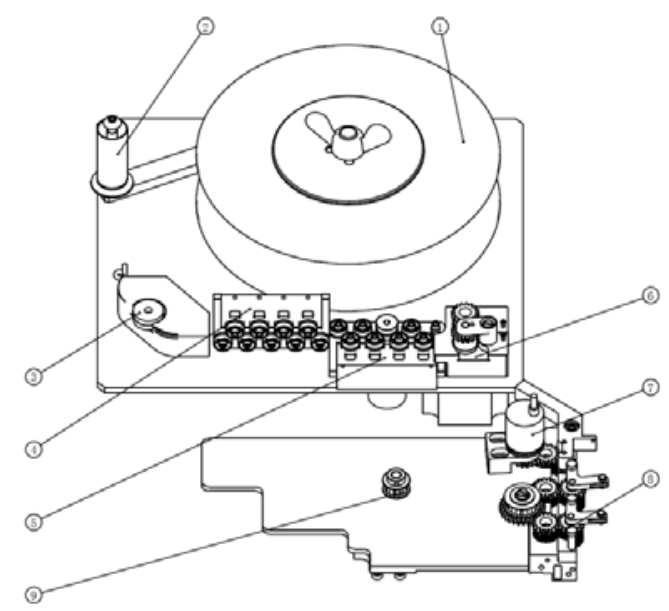

1-Reel stand;2-Wire sealing guide wheel;

3-Dust removal components;4、5-Straightener;6-Pull line device 1;

7-Encoder components;8-Automatic cable device 2;9-Drive the sync wheel

FIGURE VI. AUTOMATIC WIRE FEEDING MECHANISM

The wire feeding device consists of three parts, including the reel bracket 1 , the wire sealing guide wheel 2 and the dust removing unit 3 (see Figure 6).The wire tray bracket 1 is used to fix the wire coming out of the reel in the desired direction; the dust removing unit 3 is used to remove dust from the incoming material.

The straightening device consists of two parts, the horizontal straightener 4 and the vertical straightener 5 (see Figure 7 in the left).The straightener is arranged in two rows by a number of straightening wheels, and the two rows of straightening wheels are staggered.The horizontal direction straightener the horizontal direction of the sealing wire, and the straightener will straighten the vertical direction of the sealing wire in the vertical direction.After the wire has been through the horizontal and vertical straightening device, you can get a straight wire.

As shown in the right figure of Figure 7, the cable motor is driven by a drive motor and two runners. The drive motor is powered, a runner and a motor are connected, and the motor is rotated together, and the other is transmitted through the gear. The sealing wire passes through the middle of the two wheels, and when the motor drives the two wheels, the wire is advanced or retreated under the action of friction. When not working, the distance between the two wheels increases, and the wire is not in contact with the wheel. This device is used for wire cutting, the sealing wire automatically into the feed line system.

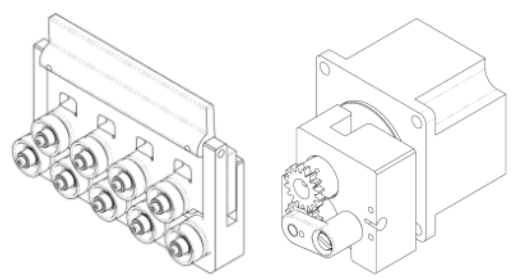

FIGURE VII. STRAIGHTENER STRUCTURE AND PULL LINE DEVICE

As shown in Figure 8, the left side shows the encoder assembly of the fixed-length device, which is used to determine the length of the wire, which consists of an encoder and three wheels.A wheel is a driving wheel, connected to the encoder by gear and moving together, and the other two are driven wheels. When the winding movement is driven, the encoder rotates together, and the encoder converts the linear displacement into an electrical signal, and the computer can know the length of the wire.

The right side of Figure 8 shows the automatic cable device 2 , used to automatically send out the wire, by the motor, driven synchronous wheel, driven synchronous wheel, gear, two sets of wire wheel. Two sets of clip wheels with a small tooth, both to increase the friction with the wire to prevent slipping, but also does not damage the wire.The motor provides power to the device and is transmitted to the two sets of clamp wheels via the timing belt.

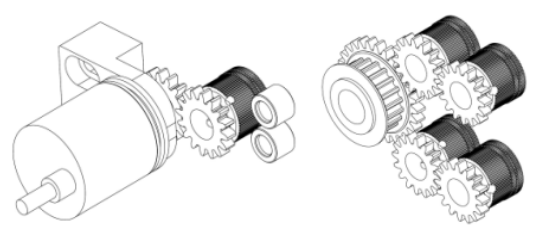

FIGURE VIII. ENCODER COMPONENTS AND AUTOMATIC CABLE DEVICE 2 


\section{Design of SEAL AND Guide Mechanism}

Seal diversion mechanism shown in Figure 9, mainly composed of four parts: Vibration feeding components, four-bit dial mechanism, laser marking machine, two-dimensional code camera. When working, the material in turn through four parts.

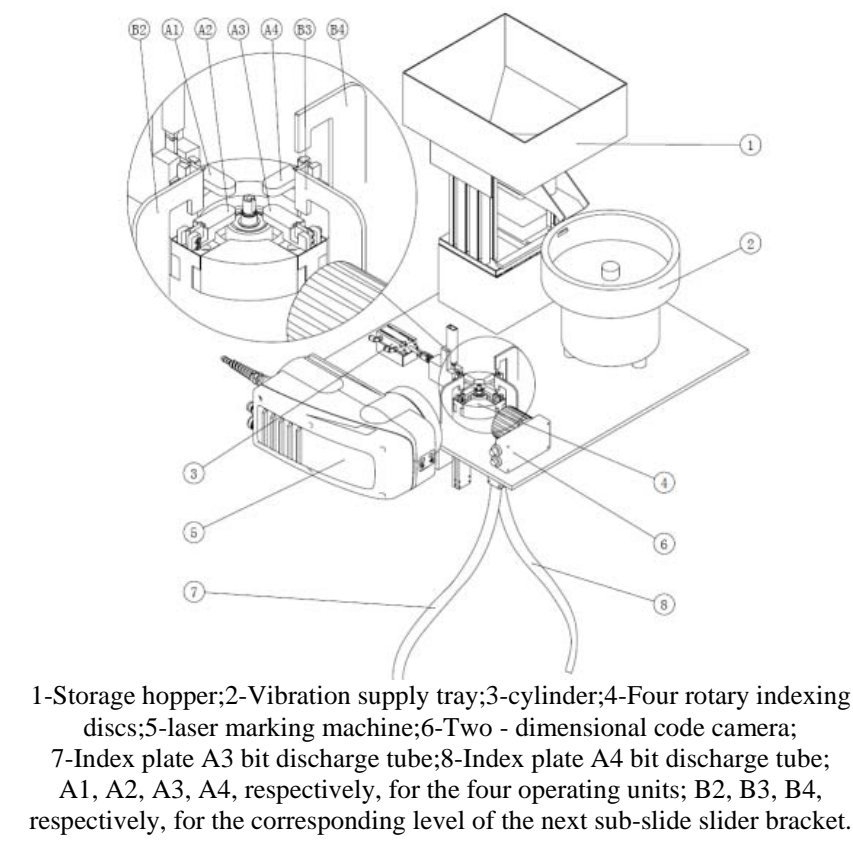

\section{FIGURE IX. SEAL GUIDE MECHANISM}

The vibration feed assembly consists of two parts: the storage hopper 1 and the vibration supply tray 2.No. 2 vibration supply tray is supplied by vibration, the irregular materials in accordance with our requirements in a certain order from the discharge port delivery.If the vibration plate is not enough, the storage hopper will supply the material of the vibration supply tray.

Four degree dial mechanism consists of the cylinder 3 , the four-position rotary indexing plate 4 , the indexing plate A3 and the A4 output pipe, A2, A3, A4 indexing plate corresponding to the structure of the material slider bracket.The cylinder 3 pushes the parts near the A1 station to the specified position. When the index is circled 4 , the material is sent to A2/A3/A4 station in turn.If the material of a station A2/A3/A4 needs to move downward from the indexing disc, the material is moved off the indexing disc by downward movement of the lower slider.The data of the indexing plates A3 and A4 are moved from the discharge pipe 7 and the discharge pipe 8 to the next working position.

The laser marking machine 5 is two-dimensional code for the material, for the management of materials. The twodimensional code camera 6 scans the two-dimensional code on the material, reads the material status of the material, and tracks the production status of each material.

When the feed system is in operation, the vibration supply tray 2 is supplied by vibration (if the vibration plate is not enough, the storage hopper will supply the material of the vibration supply tray), and the irregular material will be made to meet our requirements. A certain order from the discharge port to transport out, flow to the No. 4 dial A1 work bit, by the No. 3 cylinder to push it into the development of work.After the material reaches the A1 position, the No. 5 laser marking machine will mark the material in two-dimensional code.Marking a good material from the dial to rotate $90^{\circ}$ to A2 working position, by the No.6 two-dimensional code camera to check, check the printed code is the code we need and test the height of the material is qualified.If unqualified, B2 down the slider bracket will be pressed, the material from the bottom of the A2 station directly removed; qualified products from the index plate to the $\mathrm{A} 3$ or $\mathrm{A} 4$ rotation, through the $\mathrm{B} 3$ or $\mathrm{B} 4$ under the slider bracket Pressure, so that the material from the No. 7 or 8 , the supply pipe to the follow-up station to use.

\section{CONCLUDING REMARKS}

The automatic sealing system designed in this paper solves the problem of the feasibility and stability of automatic threading. It has the characteristics of complete function, high degree of automation, precision of organization, accurate control, advanced technology and stable work.In addition, the automatic sealer of the overall use of modular design, making the subsequent maintenance and maintenance becomes more relaxed and simple.

Seal by the automatic sealing system sealed in the energy meter, the seal of the damage is difficult, broken traces easy to identify, forging difficult, not easy to imitate, forging high cost, with the leading domestic security and anti-tampering effect.The successful application of the automatic sealing system of the energy meter in the verification pipeline to achieve the metering center of the energy meter of the large number of automatic sealing needs, can be widely used in the country's major smart grid companies, completely replace the traditional manual mode of operation, thereby increasing productivity, For China's smart grid technology to improve the overall level to make a greater contribution.The application and promotion of the system to the power grid company to achieve the whole process of energy meter, fully automated test has a guiding significance and promote the role.

\section{REFERENCES}

[1] PEI Li-jun.Design and Application of Electronic Seal Management System [J]. Electronic Technology and Software Engineering, 2015,6:121-121.

[2] Weicun, Yujie. Research on the recognition method of electric energy meter lead title based on the fuzzy image processing[J]. International Technology Management, 2015, 6:125-127.

[3] FAN Lei, LUO Qiang.Study on Sealing Technology of Fully Automatic Verification System Based on Improved Intelligent Energy Meter [J]. Industrial Measurement, 2012, s2: 153-155.

[4] WANG Yue-zhi, ZHENG An-gang, ZOU He-ping, BAI Di, LIU Feng.Study on intelligent anti-tamper technology [J].Journal of Shenyang Institute of Engineering (Natural Science Edition), 2013, 9(4):319-322.

[5] HE Zhi-qiang, XU Si-qiang, DING Tao, WANG Yong, HUANG Wei.Study on Realization of Automatic Seal of Electric Energy Meter [J]. Electrical Measurement and Instrumentation, 2011, 12:83-85.

[6] Design and Realization of Electricity Seal Seal Automatic System [J]. Manufacturing Automation, Harbin Institute of Technology, Harbin 150001, China), 2011, 33(18):145-148. 